\section{Necrotizing fasciitis of the abdominal wall caused by Serratia marcescens}

\author{
Naheed A. Lakhani, ${ }^{1}$ \\ Umesh Narsinghani, ${ }^{2}$ Ritu Kumar ${ }^{3}$ \\ 'Department of Family and Preventive \\ Medicine, Emory University School of \\ Medicine, Dunwoody, GA; 'Department \\ of Pediatrics, Mercer University School \\ of Medicine, Macon, GA; ${ }^{3}$ Department of \\ Internal Medicine Mercer University \\ School of Medicine, Macon, GA, USA
}

\section{Abstract}

In this article, we present the first case of necrotizing fasciitis affecting the abdominal wall caused by Serratia marcescens and share results of a focused review of $S$. marcescens induced necrotizing fasciitis. Our patient underwent aorto-femoral bypass grafting for advanced peripheral vascular disease and presented 3 weeks postoperatively with pain, erythema and discharge from the incision site in the left lower abdominal wall and underwent multiple debridement of the affected area. Pathology of debrided tissue indicated extensive necrosis involving the adipose tissue, fascia and skeletal muscle. Wound cultures were positive for Serratia marcescens. She was successfully treated with antibiotics and multiple surgical debridements. Since necrotizing fasciitis is a medical and surgical emergency, it is critical to examine infectivity trends, clinical characteristics in its causative spectrum. Using PubMed we found 17 published cases of necrotizing fasciitis caused by Serratia marcescens, and then analyzed patterns among those cases. Serratia marcescens is prominent in the community and hospital settings, and information on infection presentations, risk factors, characteristics, treatment, course, and complications as provided through this study can help identify cases earlier and mitigate poor outcomes. Patients with positive blood cultures and those patients where surgical intervention was not provided or delayed had a higher mortality. Surgical intervention is a definite way to establish the diagnosis of necrotizing infection and differentiate it from other entities.

\section{Introduction}

Necrotizing fasciitis, also known as flesh- eating disease, is a rare infection of the deeper layers of skin and subcutaneous tissues, and easily spreads across the fascial plane within those tissues. As bacterial toxins and the immune response cause vasoconstriction of the vasculature, the fascial spaces become avascular resulting in necrosis, which also prevents penetration of antibiotics into the tissues. ${ }^{1}$ Common causes are Group A streptococcus (GAS) (Streptococcus pyogenes), Staphylococcus aureus, Vibrio vulnificus, Clostridium perfringens, and Bacteroides fragilis. Mortality ranges from 4.2 to $38 \%$ with improving prognosis as time to treatment decreases. ${ }^{2}$

Serratia marcescens, a motile bacillus, gramnegative, facultative anaerobe, is an opportunistic pathogen of increasing importance. It is part of normal colon flora, and is also found in soil, sewage, and water. This Enterobacteriaceae organism also typically colonizes the respiratory and urinary tracts and causes infections in those organ systems. ${ }^{3} S$. marcescens is often an opportunistic infection and may cause osteomyelitis, septic arthritis, endocarditis, and, rarely cellulitis or necrotizing fasciitis. ${ }^{4-6}$ Soft tissue infections due to gram-negative organisms are relatively uncommon, and typical predisposing factors include: a history of trauma, alcoholism, peripheral vascular disease, systemic lupus erythematosus, immunosuppression, diabetes mellitus, urinary tract infection (UTI), bacteremia, pneumonia, infective arthritis, burns, and renal failure..$^{4,7}$ Other predisposing factors include: antibiotic use (most often first generation cephalosporins), steroid use, surgical instrumentation, urinary catheters, respiratory equipment, intravenous lines, injections, lacerations, abscesses, or ulcers. ${ }^{8}$

Common presentations of necrotizing fasciitis within 48 hours of infection include skin erythema and swelling at the affected site (97.6\%), pyrexia (61.9\%), hypotension (33.3\%), altered consciousness (28.6\%), bullous lesions (26.2\%), and crepitus (9.5\%). Hypotension, altered consciousness, ventilator support, ALT > two-fold of normal, serum creatinine $>177 \mu \mathrm{mol} / \mathrm{L}$, thrombocytopenia $\left(<100 \times 10^{9} / \mathrm{L}\right)$, and worsening symptoms within 48 hours of admission have been associated with higher fatality rates. ${ }^{9}$ Lack of response to narrow-spectrum antibiotics, bullae formation, or a rapidly worsening clinical course, should heighten the suspicion for uncommon organisms like $S$. marcescens.

Reports of $S$. marcescens necrotizing fasciitis cases have increased in the literature. In this study, we identify characteristics, trends, and risk factors of those infections to better prepare the medical community and prevent poor outcomes.
Correspondence: Department of Family and Preventive Medicine, Emory University School of Medicine, 4500 North Shallowford Road, Dunwoody, Georgia 30338, USA.

Tel.: + 1.404.542.7238 / +1.404.778.6920

Fax: +1.404.778.6901.

E-mail: naheeda786@gmail.com

Key words: $S$. Marcescens, necrotizing fasciitis, community acquired infection, healthcare associated infection, surgical intervention.

Acknowledgments: we thank our case patient, the hospital, and other doctors involved in the care of this case patient.

Contributions: the authors contributed equally.

Conflict of interest: the authors declare no potential conflict of interest.

Received for publication: 22 December 2014.

Revision received: 9 February 2015.

Accepted for publication: 10 February 2015.

This work is licensed under a Creative Commons Attribution NonCommercial 3.0 License (CC BYNC 3.0).

(C) Copyright N.A. Lakhani et al., 2015 Licensee PAGEPress, Italy

Infectious Disease Reports 2015; 7:5774

doi:10.4081/idr.2015.5774

\section{Materials and Methods}

PubMed was used to search for cases of necrotizing fasciitis caused by Serratia marcescens published in the English language literature between 1966 and 2013. Keywords that were used included: Serratia marcescens, necrotizing, and fasciitis. We identified eleven additional cases of necrotizing fasciitis due to $S$. marcescens in the literature since the latest review in 2001, which are included in Table 1.,7,10-22 Cases were categorized as being healthcare-associated infections or community-acquired infections based on the Centers for Disease Control and Prevention (CDC) definition of healthcare-associated infections (HAIs) as infections that patients acquire during the course of receiving healthcare treatment for other conditions. ${ }^{23}$

\section{Case Report}

We recently identified a case involving a 51year-old African-American woman who pre- 
sented 3 weeks postoperatively after undergoing a bifemoral bypass and left distal femoral aneurysm repair for symptomatic peripheral vascular disease. She had a long standing history of smoking and hypertension. On presentation, the patient reported having fever, chills, nausea, vomiting, and diarrhea for 6 days, redness and odorous discharge from her surgical incision site for one day. Additional history revealed that she was cleaning her wound with well water. On examination, there was erythema extending from the periumbilical area to her left groin, along with severe tenderness to palpation in that area. No crepitus was felt on palpation. Her temperature on admission was $36.9^{\circ} \mathrm{C}$, blood pressure was $162 / 109 \mathrm{mmHg}$, respirations were 24 breaths per minute, and she was in no acute distress. Her white blood cell count was $9.8 \times 10^{9} / \mathrm{L}, \mathrm{C}$ reactive protein (CRP) was $16.57 \mathrm{nmol} / \mathrm{L}$, serum creatine kinase level was $57 \mathrm{U} / \mathrm{L}$, serum electrolytes, renal, liver functions and immunoglobulin levels were normal and blood and urine cultures were negative. The patient was started on intravenous vancomycin and meropenem and underwent multiple debridements of the abdominal wound and left groin region. Intraoperative findings confirmed the presence of deep necrotic fascia and non-adherent subcutaneous tissue. Histopathology of debrided tissue indicated acute and chronic inflammation with infiltration of granulocytes and necrosis involving the fibroadipose tissue and skeletal muscle. Intraoperative wound cultures were positive for Serratia marcescens. Based on sensitivities, antibiotics were changed to intravenous levofloxacin MIC $<2 \mathrm{mcg} / \mathrm{mL}$. She also received negative-pressure wound therapy using vacuum assisted closure. The patient improved clinically and was successfully dis- charged on oral levofloxacin to complete a total of 3 weeks of treatment.

\section{Results}

Since 1966, there have been 17 documented cases of necrotizing fasciitis caused by $S$. marcescens (Table 1).,7,10-22 Eight (47\%) of those cases occurred within the past five years. ${ }^{4,715-24}$ Among all of the identified cases, 10 (59\%) impacted a leg, and 1 (5.9\%) affected the forearm, the cervical spine, the axilla and chest wall, a venous access site, the oropharynx, the chest wall, or the lower abdomen. Thirteen (77\%) of the cases had blood cultures that were positive for $S$. marcescens. Ten cases (59\%) were community-acquired infections,

Table 1. Serratia marcescens necrotizing fasciitis cases, 1966 to present.

\begin{tabular}{|c|c|c|c|c|c|c|c|c|c|c|}
\hline Author & Year & Age & Sex & $\begin{array}{l}\text { Risk } \\
\text { factors }\end{array}$ & $\begin{array}{l}\text { Precipitating } \\
\text { factor }\end{array}$ & $\begin{array}{l}\text { Site of } \\
\text { infection }\end{array}$ & Type & $\begin{array}{l}\text { S. marcescens } \\
\text { cultures }\end{array}$ & Treatment & Outcome \\
\hline Rimailho et al. ${ }^{10}$ & 1987 & 74 & M & Immunocompromized & Dilofenac consumption & Leg & $\mathrm{CA}$ & Blister and blood & None & Died \\
\hline Bornstein et al. ${ }^{11}$ & 1992 & 37 & $\mathrm{~F}$ & $\begin{array}{c}\text { Renal failure } \\
\text { on hemodialysis }\end{array}$ & $\begin{array}{l}\text { Pain during } \\
\text { dialysis }\end{array}$ & $\begin{array}{l}\text { Axilla and } \\
\text { chest wall }\end{array}$ & $\mathrm{HA}$ & Wound, bullae, blood & Antibiotics and SD & Recovered \\
\hline Zipper et al. ${ }^{12}$ & 1996 & 55 & $\mathrm{~F}$ & Diabetes & Left below-knee amputation & Leg & $\mathrm{CA}$ & Wound & Antibiotics & Recovered \\
\hline Huang et al. ${ }^{13}$ & 1999 & 73 & M & Nephrotic syndrome & Steroid therapy & Lower leg & $\mathrm{HA}$ & Necrotic tissue, blood & Antibiotics and SD & Recovered \\
\hline Huang et al. ${ }^{13}$ & 1999 & 40 & M & $\begin{array}{l}\text { Uremia, } \\
\text { peritoneal dialysis, } \\
\text { SLE }\end{array}$ & $\begin{array}{l}\text { Pneumonia with + } \\
\text { cultures for } \\
\text { S. marcescens, } \\
\text { steroid and }\end{array}$ & $\begin{array}{l}\text { Left calf } \\
\text { and thigh }\end{array}$ & $\mathrm{CA}$ & $\begin{array}{c}\text { Necrotic } \\
\text { tissue, blood }\end{array}$ & Antibiotics and SD & Recovered \\
\hline
\end{tabular}

\begin{tabular}{|c|c|c|c|c|c|c|c|c|c|c|}
\hline Liangpunsakul et al. ${ }^{14}$ & 2001 & 66 & $\mathrm{~F}$ & Healthy & None & Leg & $\mathrm{CA}$ & Blood & Antibiotics & Died \\
\hline Newton et al. ${ }^{15}$ & 2002 & 2 & $\mathrm{~F}$ & Healthy & Pharyngitis & Cervical spine & $\mathrm{CA}$ & Wound, blood & Antibiotics and SD & Died \\
\hline Bachmeyer et al. ${ }^{16}$ & 2004 & 49 & M & $\begin{array}{c}\text { Small cell } \\
\text { lung cancer, DM }\end{array}$ & $\begin{array}{l}\text { Chemotherapy } \\
\text { and cellulitis }\end{array}$ & Right leg & $\mathrm{HA}$ & Tissue, bullae, blood & Antibiotics & Recovered \\
\hline Curtis et al. ${ }^{4}$ & 2005 & 51 & M & ESRD, T2DM, CHF & Scraped knee on rock in river & Left leg & $\mathrm{CA}$ & Wound, blood & Antibiotics and SD & Died \\
\hline Statham et al. ${ }^{17}$ & 2009 & 6 & M & Immunocompetent & Suspected pharyngitis & Oro-pharynx & $\mathrm{CA}$ & Wound, blood & Antibiotics and SD & Recovered \\
\hline Motsitsi et al. ${ }^{18}$ & 2011 & 37 & M & Healthy & Human bite & Forearm & $\mathrm{CA}$ & Wound & SD & Died \\
\hline Vano-Galvan et al. ${ }^{7}$ & 2012 & 57 & $\mathrm{~F}$ & ML, immunocompromized & Minor trauma & Right thigh & $\mathrm{HA}$ & Blister, blood & Antibiotics & Died \\
\hline Prelog et al. ${ }^{19}$ & 2012 & 15 & $\mathrm{~F}$ & $\begin{array}{c}\text { Acute lymphocyctic } \\
\text { leukemia }\end{array}$ & $\begin{array}{l}\text { Venous access port } \\
\text { implantation }\end{array}$ & $\begin{array}{c}\text { Left axilla, } \\
\text { venous HA } \\
\text { access port site }\end{array}$ & Wound & Antibiotics and SD & Recovered & \\
\hline
\end{tabular}

\begin{tabular}{|c|c|c|c|c|c|c|c|c|c|c|}
\hline Wen et al. ${ }^{20}$ & 2012 & 40 & $\mathrm{~F}$ & $\begin{array}{l}\text { Nephrotic syndrome, } \\
\text { cyclosporine use }\end{array}$ & $\begin{array}{l}\text { Chemotherapy } \\
10 \text { daysprior }\end{array}$ & Left leg & CA & Wound, blood & Antibiotics & Died \\
\hline Rehman et al. ${ }^{21}$ & 2012 & 54 & $\mathrm{~F}$ & $\begin{array}{l}\text { SLE, end-stage } \\
\text { renal disease }\end{array}$ & $\begin{array}{c}\text { Central venous catheter, } \\
\text { AV fistula ligation, } \\
\text { steroid therapy }\end{array}$ & Chest wall & $\mathrm{HA}$ & Wound, blood & Antibiotics and SD & Died \\
\hline
\end{tabular}

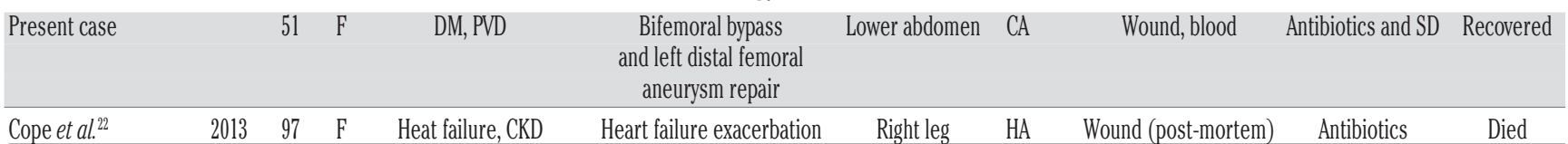

SD, Surgical debridement; CA, community-acquired infection; HA, healthcare-associated infection; SLE, systemic lupus erythematosus; ESRD, end-stage renal disease; T2DM, Type II, diabetes mellitus; PVD, peripheral vascular disease. 
and 7 cases (41\%) were healthcare-associated infections. An overwhelming number of cases (81.3\%) had pre-existing open wounds. Seven cases (41\%) were immunocompromized, 5 cases (29\%) had kidney disease, and 4 cases (24\%) had diabetes. A majority (59\%) of the cases were among females. Three of the cases (18\%) were children.

Nine out of seventeen cases (53\%) died as a result of necrotizing fasciitis and its complications. Six of the cases (67\%) that died had community-acquired infections. Individuals with positive versus negative blood cultures were more likely to die ( $88 \%$ vs. $75 \%)$. Patients who did not receive surgical debridement had inferior outcomes; they had a mortality of $71 \%$ compared to $40 \%$ among those who received surgical intervention as opposed to debridement. Additionally, all patients $(18 \%, \mathrm{n}=3)$ who received only antibiotics and the one patient who received only surgical debridement died. All previously healthy patients $(18 \%, n=3)$ also died. A majority of those that recovered had a surgical procedure in the hospital prior to symptom onset such as below the knee amputation or venous access port implantation $(75 \%, \mathrm{n}=8)$.

\section{Discussion and Conclusions}

Necrotizing fasciitis is a deep infection of the subcutaneous tissue that results in progressive destruction of fascia and fat. The disease is classified as type I (polymicrobial infection), type II (monomicrobial) and type III gas gangrene, or clostridial myonecrosis. Type I infection involves anaerobic species in combination with one or more facultative anaerobic streptococci (other than group A) and members of the Enterobacteriaceae family. Type II infection is commonly caused by group A streptococci or other beta-hemolytic streptococci that are isolated alone or in combination with other species, most frequently $S$. aureus. These infections are also commonly referred as flesh eating infection. Among those with necrotizing fasciitis, the affected area is typically erythematous, swollen, warm, and exquisitely tender. The infection progresses rapidly over several days, with changes in skin color from red-purple to patches of blue-gray. Skin breakdown with bullae (containing thick pink or purple fluid) and frank cutaneous gangrene may be observed within three to five days. ${ }^{16}$ The development of anesthesia may precede the appearance of skin necrosis and provide a clue that the process is necrotizing fasciitis rather than cellulitis. In advanced infection, high fever and systemic toxicity are generally observed.

Individuals with positive blood cultures typically have poorer prognosis and higher mortal- ity rates. ${ }^{1,25}$ Treatment of necrotizing infection consists of early and aggressive surgical exploration and debridement of necrotic tissue, together with broad spectrum empiric antibiotic therapy and hemodynamic support as necessary. ${ }^{4,26}$ Acceptable antibiotic regimens prior to identification of the causative organism(s) include administration of a carbapenem or beta-lactam/beta-lactamase inhibitor, together with clindamycin (600 to 900 milligrams intravenously every eight hours), as well as an agent with activity against MRSA. Definitive antibiotic treatment should be tailored according to blood and or tissue gram stain, culture, and sensitivity results when available. ${ }^{27}$ If $S$. marcescens is identified as the main pathogen, third-generation cephalosporins, fluoroquinolones, and imipenem/cilastatin are the antimicrobials of choice. Our patient's fever on presentation was likely masked by the pain medications she was taking, though she did give a history of having fever at home. She most likely had a subacute course and thus lacked the classic features of rapid clinical progression and fulminant toxicity. An HIV test was not performed, as the patient did not have any risk factors or any previous sexually transmitted disease. Our review noted a mortality rate of $53 \%$ among those with $S$. marcescensinduced necrotizing fasciitis, which is higher than the mortality rate reported by Elliott $e t$ $a l^{28}$ in 1996 and nearly equivalent (53\% vs. $50 \%)$ to the mortality rate documented by Nancy et al. in $2002 .{ }^{29}$ Patients who died were more likely to have positive blood cultures, present with a community-acquired illness, be previously healthy, experience minor trauma or sickness prior to symptom onset, and not receive both surgical debridement and antibiotic therapy. Similar observations of increased mortality among those with positive blood cultures or those not receiving appropriate antibiotic and surgical treatment were also found in other studies. ${ }^{4,26}$ Increased mortality among individuals with less severe injury, lack of traditional risk factors, and those who did not have a recent surgical procedure in the hospital may have been due to less vigilance about changes in health status and the fact that $S$. marcescens is common in the outdoor environment; these individuals were also more likely to have community-acquired infections (70\% vs. 30\%). Additionally, individuals who had been hospitalized recently were more likely to have received antibiotics in the near past and also more likely to be wary of any new symptoms. Healthy patients also tend to seek care later and receive less aggressive treatment; only one of the previously healthy patients received both antibiotics and surgical debridement.

Clinicians should be wary of necrotizing fasciitis among those with soft tissue infections presenting after environmental open skin exposure. Gram-negative bacilli, including $S$. marcescens, should especially be considered in cases of necrotizing fasciitis or cellulitis among immunocompromized persons with renal failure, steroid use, recent surgery or diabetes. ${ }^{29}$ Early diagnosis is key, but unfortunately is missed in 85 to $100 \%$ of cases since necrotizing fasciitis is often confused with cellulitis, myositis, or deep-seated abscess(es). A high index of suspicion is important in view of the paucity of specific cutaneous findings early in the course of the disease. Radiographic imaging studies may be useful in determining if muscle tissue is involved but should not delay surgical intervention. Our case also underscores the importance of preoperative and more so, postoperative wound care education, which could have potentially prevented this fatal complication. ${ }^{30}$ The most effective treatment regimen for suspected necrotizing fasciitis includes: early and aggressive surgical exploration and debridement, immediate broad spectrum empiric antibiotic therapy, and hemodynamic support as necessary. ${ }^{4,26}$

\section{References}

1. Childers BJ, Potyondy LD, Nachreiner R, et al. Necrotizing fasciitis: a fourteen-year retrospective study of 163 consecutive patients. Am Surg 2002;68:109-16.

2. Bilton BD, Zibari GB, McMillan RW, et al. Aggressive surgical management of necrotizing fasciitis serves to decrease mortality: a retrospective study. Am Surg 1998;64: 397-400.

3. Hejazi A, Falkiner FR. Serratia marcescens. J Med Microbiol 1997;46:90312.

4. Curtis CE, Chock S, Henderson T, Holman MJ. A fatal case of necrotizing fasciitis caused by Serratia marcescens. Am Surg 2005;71:228-30.

5. Yu VL. Serratia marcescens: historical perspective and clinical review. New Engl J Med 1979;300:887-93.

6. Liangpunsakul S, Pursell K. Communityacquired necrotizing fasciitis caused by Serratia marcescens: case report and review. Eur J Clin Microbiol Infect Dis 2001;20:509-10.

7. Vano-Galvan S, Alvarez-Twose I, MorenoMartin P, Jaen P. Fulminant necrotizing fasciitis caused by Serratia marcescens in an immunosuppressed host. Int J Dermatol 2014;53:e57-8.

8. Acar JF. Serratia marcescens infections. Infect Control 1986;7:273-8.

9. Hung CC, Chang SC, Lin SF, et al. Clinical manifestations, microbiology and prognosis of 42 patients with necrotizing fasciitis. J Formos Med Assoc 1996;95:917-22. 
10 Rimailho A, Riou B, Richard C, Auzepy P. Fulminant necrotizing fasciitis and nonsteroidal anti-inflammatory drugs. J Infect Dis 1987;155:143-6.

11. Bornstein PF, Ditto AM, Noskin GA. Serratia marcescens cellulitis in a patient on hemodialysis. Am J Nephrol 1992;12:374-6.

12. Zipper RP, Bustamante MA, Khatib R. Serratia marcescens: a single pathogen in necrotizing fasciitis. Clin Infect Dis 1996;23:648-9

13. Huang JW, Fang CT, Hung KY, et al. Necrotizing fasciitis caused by Serratia marcescens in two patients receiving corticosteroid therapy. J Formos Med Assoc 1999;98:851-4.

14. Liangpunsakul S, Pursell K. Communityacquired necrotizing fasciitis caused by Serratia marcescens: case report and review. Eur $\mathrm{J}$ clin microbiol infect dis 2001;20:509-10.

15. Newton CL, deLEMOS D, Abramo TJ, et al. Cervical necrotizing fasciitis caused by Serratia marcescens in a 2 year old. Pediatr Emerg Care 2002;18:433-5.

16. Bachmeyer C, Sanguina M, Turc Y, et al. Necrotizing fasciitis due to Serratia marcescens. Clin Exp Dermatol 2004:6734.
17. Statham MM, Vohra A, Mehta DK, et al. Serratia marcescens causing cervical necrotizing oropharyngitis. Int J Pediatr Otorhinolaryngol 2009;73:467-73.

18. Motsitsi NS. Fatal necrotizing fasciitis following human bite of the forearm. J Hand Surg 2011;36(605.

19. Prelog T, Jereb M, Cucek I, Jazbec J. Necrotizing fasciitis caused by Serratia marcescens after venous access port implantation in a child with acute lymphoblastic leukemia. J Pediatr Hematol Oncol 2012;34:e246-8.

20. Wen YK. Necrotizing fasciitis caused by Serratia marcescens: a fatal complication of nephrotic syndrome. Renal Failure 2012;34:649-52.

21. Rehman T, Moore TA, Seoane L. Serratia marcescens necrotizing fasciitis presenting as bilateral breast necrosis. J Clin Microbiol 2012;50:3406-8.

22. Cope TE, Cope W, Beaumont DM. A case of necrotising fasciitis caused by Serratia marsescens: extreme age as functional immunosuppression? Age Ageing 2013;42:266-8.

23. Centers for Disease Control and Prevention. Healthcare-associated infections (HAIs). Available from: http:/www.cdc.gov/HAI/surveillance/
24. Lancerotto L, Tocco I, Salmaso R, et al. Necrotizing fasciitis: classification, diagnosis, and management. J Trauma Acute Care Surg 2012;72:560-6.

25. Chen IC, Li WC, Hong YC, et al. The microbiological profile and presence of bloodstream infection influence mortality rates in necrotizing fasciitis. Crit Care 2011;15:R152.

26. McHenry CR, Piotrowski JJ, Petrinic D, Malangoni MA. Determinants of mortality for necrotizing soft-tissue infections. Ann Surg 1995;221:558-65.

27. Schwartz MN. Cellulitis and subcutaneous tissue infections. In: Mandell GL, Bennett JE, Dolin R, eds. Principles and practice of infectious diseases. 6th ed. Philadelphia: Churchill Livingstone; 2005. p 1172.

28. Elliott DC, Kufera JA, Myers RA. Necrotizing soft tissue infections. Risk factors for mortality and strategies for management. Ann Surg 1996;224:672-83.

29. Nancy F. Crum MRW. Serratia marcescens Cellulitis: a case report and review of the literature. Infect Dis Clin Pract 2002;11.

30. Ronco M, Iona L, Fabbro C, et al. Patient education outcomes in surgery: a systematic review from 2004 to 2010. Int J Evid Based Healthc 2012;10:309-23. 